\title{
Treatment of Obesity-Related Complications with Novel Classes of Naturally Occurring PPAR Agonists
}

\author{
Josep Bassaganya-Riera, Amir J. Guri, and Raquel Hontecillas \\ Nutritional Immunology and Molecular Medicine Laboratory, Virginia Bioinformatics Institute, \\ Virginia Polytechnic Institute and State University, Blacksburg, VA 24061, USA \\ Correspondence should be addressed to Josep Bassaganya-Riera, jbassaga@vt.edu
}

Received 27 April 2010; Revised 25 July 2010; Accepted 2 December 2010

Academic Editor: Luc F. Van Gaal

Copyright ( $\odot 2011$ Josep Bassaganya-Riera et al. This is an open access article distributed under the Creative Commons Attribution License, which permits unrestricted use, distribution, and reproduction in any medium, provided the original work is properly cited.

\begin{abstract}
The prevalence of obesity and its associated comorbidities has grown to epidemic proportions in the US and worldwide. Thus, developing safe and effective therapeutic approaches against these widespread and debilitating diseases is important and timely. Activation of peroxisome proliferator-activated receptors (PPARs) $\alpha, \gamma$, and $\delta$ through several classes of pharmaceuticals can prevent or treat a variety of metabolic and inflammatory diseases, including type II diabetes (T2D). Thus, PPARs represent important molecular targets for developing novel and better treatments for a wide range of debilitating and widespread obesityrelated diseases and disorders. However, available PPAR $\gamma$ agonistic drugs such as Avandia have significant adverse side effects, including weight gain, fluid retention, hepatotoxicity, and congestive heart failure. An alternative to synthetic agonists of PPAR $\gamma$ is the discovery and development of naturally occurring and safer nutraceuticals that may be dual or pan PPAR agonists. The purpose of this paper is to summarize the health effects of three plant-derived PPAR agonists: abscisic acid (ABA), punicic acid (PUA), and catalpic acid (CAA) in the prevention and treatment of chronic inflammatory and metabolic diseases and disorders.
\end{abstract}

\section{Introduction}

During the past two decades, the prevalence of obesity has risen to epidemic proportions in the United States, and current estimates indicate that approximately $67 \%$ of the population is overweight and one-third is obese. This burgeoning problem has brought with it numerous health and fiscal concerns. Obesity is associated with a number of chronic diseases such as type II diabetes (T2D), cardiovascular disease (CVD), chronic kidney disease (CKD), nonalcoholic fatty liver disease (NAFLD), obstructive sleep apnea (OSA), gallbladder diseases, and various types of cancers [1], and obesity-related spending is currently estimated at $\$ 147$ billion per year [2]. This number has been anticipated to rise to $\$ 344$ billion, or $21 \%$ of all health care spending, in 2018 if rates continue on their current trajectory [3].

PPARs are the receptors for endogenous lipid molecules (i.e., prostaglandins or hydroxy-containing PUFA such as 12/15-hydroxyeicosatetraenoic (HETE), 13-hydroxyoctadecadienoic (HODE)) molecular targets for drugs against type 2 diabetes [4-6] and represent promising new targets for the treatment and prevention of inflammatory disorders such as IBD $[7,8]$. PPARs belong to the superfamily of nuclear hormone receptors with 48 members identified in the human genome. There are three known PPAR isoforms; $\alpha, \beta$ or $\delta$, and $\gamma$, which differ in their tissue distribution and functional activity [9]. Functionally, PPARs regulate inflammation, immunity, and metabolism [10]. PPAR activation and expression is controlled by a diverse set of natural and synthetic molecules, including nutrients, nonnutrient endogenous ligands, and drugs (i.e., thiazolidinediones (TZDs) and fibrates).

Activation of the nuclear receptor peroxisome proliferator-activated receptor $\gamma$ (PPAR $\gamma$ ) has shown efficacy in the treatment of type II diabetes [11], inflammatory bowel disease [12, 13], colorectal cancer [14, 15], and influenza virus-induced pulmonary inflammation [16]. Thiazolidinediones (TZDs) are highly efficacious in activating PPAR $\gamma$, but the key representative of this class of drugs, rosiglitazone (Avandia), is associated with significant adverse side effects, 


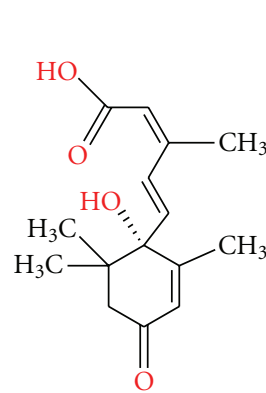

(a)

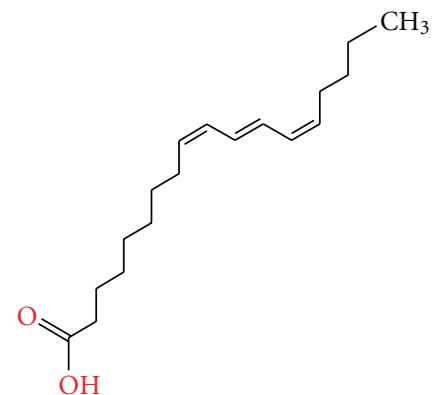

(b)

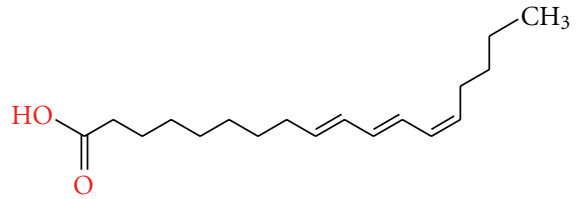

(c)

Figure 1: Chemical structures of the isoprenoid abscisic acid (a) and the conjugated linolenic acid stereo- or regioisomers punicic acid- (9Z, $11 E, 13 E$-) octadeca-9, 11, 13-trienoic acid (b) and catalpic acid- (9E, 11E, 13Z-) octadeca-9, 11, 13-trienoic acid (c).

including weight gain, congestive heart failure, and fluid retention [6]. Although the results of the recent action to control cardiovascular disease in diabetes (ACCORD) trial did not report side effects associated with the use of the fibrate class of PPAR $\alpha$ agonists [17], other studies have reported that they can increase the risk for myopathy, cholelithiasis, and venous thrombosis [18]. Therefore, based on the concerns regarding cardiovascular safety of rosiglitazone, in 2010, the European Medicines Agency took rosiglitazone off the market in Europe. Moreover, the Food and Drug Administration restricted the use of rosiglitazone in the United States to situations in which other medications are not effective, thereby minimizing its use. Thus, there is an urgent need to develop novel and safer agonists of PPAR $\alpha$ and $\gamma$ as therapeutics for obesity, diabetes, inflammation, and cancer. Our group has already developed a pipeline of naturally occurring compounds that activate PPARs [12, 1926] and are both efficacious and safe, thereby confirming that in spite of the side effects of some synthetic agonists, PPARs remain valid drug/nutraceutical discovery targets. We have also set up the systems for virtually screening large compound libraries [27]. This paper describes the mechanisms of action of abscisic acid (ABA), punicic acid (PUA), and catalpic acid (CAA) (Figure 1) and their effects in mouse models of obesity, diabetes, and atherosclerosis.

\section{Abscisic Acid}

In 2009, the story of the isoprenoid phytohormone abscisic acid (ABA) and its elusive receptors were selected as runner up for "breakthrough of the year" by Science magazine [28]. This distinction awarded to ABA-research is attributable in part to the importance that ABA holds as a signaling compound. In plants, $\mathrm{ABA}$ is involved in numerous developmental and adaptive stress responses, including those related to stomatal opening and closing, pathogen defense, embryo and seed development, germination, promotion of seed desiccation tolerance and dormancy, and general growth and reproduction [29]. Researchers over the past 30 years have identified over 100 loci and numerous second messengers involved in ABA-induced responses, messengers such as calcium, reactive oxygen species (ROS), cyclic nucleotides, and phospholipids [29].
During the past few years, our laboratory and others have been investigating the potential of $\mathrm{ABA}$ as a bioactive compound for the prevention and treatment of diseases. In 2007, Bruzzone et al. found that ABA can be produced by human granulocytes and proposed that it may function as an endogenous signaling compound in mammals [30]. The signaling pathway identified by Bruzzone et al. is remarkably similar to that described in plants. The components of the pathway include a pertussis-toxin-sensitive G-proteincoupled receptor on the plasma membrane, cAMP overproduction, protein kinase A- (PKA-) induced activation of ADP-ribosyl cyclase CD38, cADP-ribose generation, and an increase in intracellular calcium [30]. The lanthionine synthetase C-like protein 2 (LANCL2), a protein which shares high-sequence homology to the ABA-binding protein GCR2, was recently recognized as being critical for ABAinduced responses in the mammalian cells [31].

Research in our laboratory has focused on in vivo effects of ABA administration. We initially determined that $A B A$ increases the activity of the nuclear receptor peroxisome proliferator-activated receptor $\gamma(\operatorname{PPAR} \gamma)$ in 3T3-L1 preadipocytes [22]. Because it has been shown to be an influential protein in a number of cells and tissues integral to glucose homeostasis, uncovering how PPAR $\gamma$ activation improves the insulin response has been a complex task. In white adipose tissue (WAT), a region which expresses high levels of PPAR $\gamma$, TZDs increase the differentiation of new adipocytes, thereby preventing adipocyte hypertrophy and lipid efflux into peripheral tissues [32]. PPAR $\gamma$ activation also inhibits macrophage and lymphocyte-induced inflammation [33], a hallmark of obesity and its comorbidities, and its presence has been shown to be important in the proper function of key metabolic regions such as skeletal muscle [34], the liver [35], and pancreas [36].

Despite the benefits associated with PPAR $\gamma$ activation, TZDs are associated with unwanted side effects, such as weight gain, fluid retention, and congestive heart failure, which diminish their appeal as therapeutic agents [6]. Recently, the TZD rosiglitazone was associated with increased risk of myocardial infarction and cardiovascular mortality although another TZD, pioglitazone (Actos), appears to be safer [37]. An objective in our research with $\mathrm{ABA}$ was to determine whether it could replicate some of the 
beneficial effects associated with PPAR $\gamma$ activation without causing adverse side effects.

\section{ABA in Type II Diabetes}

Our laboratory's first study with ABA was designed to assess its efficacy in a mouse model of obesity and diabetes [22]. $\mathrm{Db} / \mathrm{db}$ mice were fed high-fat diets containing a racemic ABA mixture at $0,100,200,400$, and $800 \mathrm{mg} / \mathrm{kg}$ diet. After a 5-week ABA supplementation, we observed significant improvements in fasting blood glucose at all doses [22]. There were no side effects noted with any of the ABA concentrations. Further testing with ABA continued with the lowest-effective dose measured $(100 \mathrm{mg} / \mathrm{kg})$. At this concentration, ABA supplementation significantly improved glucose tolerance, inhibited WAT macrophage infiltration, and reduced tumor necrosis factor $\alpha$ (TNF- $\alpha$ ) mRNA. Expressions of PPAR $\gamma$ and PPAR $\gamma$-responsive genes CD36 and aP2 were also significantly elevated in WAT of ABAfed mice in comparison to control-fed mice, indicating that ABA mimicked TZDs in their capacity to activate PPAR $\gamma$ gene regulatory mechanisms in the WAT. Also in line with increased PPAR $\gamma$ activity, the number of small adipocytes in WAT was increased, and interscapular brown adipose tissue fat pads were greater in ABA-fed mice. ABA-fed mice also had significantly small liver weights [22], an effect that may be due to increased expression of hepatic adiponectin receptors.

We next sought to further dissect the cells and tissues affected by ABA by assessing its effect on the two main fractions of WAT, adipocytes and stromal vascular cells (SVCs). The SVC fraction of the WAT, composed of immune cells, preadipocytes, and endothelial cells and fibroblasts, is a mainly non-energy storing portion of WAT that plays an important role in the tissue's homeostasis. Gene expression analyses revealed that oral ABA supplementation exerted a significantly more substantial affect on the SVCs. Levels of PPAR $\gamma$ and its responsive gene CD36 were more greatly enhanced in the SVCs than in adipocytes, and SVCs from ABA-fed mice showed a marked reduction $(\sim 15$-fold $)$ in monocyte chemoattractant protein 1 (MCP-1) mRNA and protein levels [21]. In line with decreased MCP-1, the infiltration of CCR $2^{+} \mathrm{CD} 11 \mathrm{~b}^{+} \mathrm{F} 4 / 80^{\mathrm{hi}}$ macrophages into WAT was significantly decreased by ABA [21]. Chemokine receptor 2 (CCR2) is the receptor for MCP-1, and both proteins have been associated with obesity-related inflammation and insulin resistance [38, 39].

To determine whether ABA's affects were dependent on PPAR $\gamma$, control and ABA-supplemented diets were fed to tissue-specific PPAR $\gamma$ knockout mice. The transgenic mice used in this study, PPAR $\gamma$ flfl; MMTV $\mathrm{Cre}^{+}$mice, lacked PPAR $\gamma$ in all hematopoietic and epithelial cells [12]. After 28 weeks of high-fat feeding, we found that ABA's ability to normalize glucose tolerance and reduce WAT inflammation was significantly impaired in the MMTV $\mathrm{Cre}^{+}$mice [21]. There were also no adverse side effects observed with this long-term feeding trial.

Our results show that ABA's antidiabetic effect is mediated through a PPAR $\gamma$-dependent mechanism though in vitro studies in human and rat pancreatic islet cells demonstrate that ABA-induced increases in insulin secretion are mediated through cAMP/PKA [40]. Interestingly, recent findings in our lab link PPAR $\gamma$ activation with the cAMP/PKA signaling pathway. More specifically, by using obese $\mathrm{db} / \mathrm{db}$ mice, we showed that ABA and the TZD rosiglitazone acted synergistically, rather than competitively, to reduce WAT macrophage infiltration [20]. Further, ABA's in vitro activation of PPAR $\gamma$ in 3T3-L1 preadipocytes was inhibited by the cAMP-inhibitor $2^{\prime} 5^{\prime}$ dideoxyadenosine or the PKA inhibitor 14-22 myristolated PKA-inhibitor fragment [20]. There have been previous reports indicating that PKA activation increases PPAR $\gamma$ activity [41], and together these findings indicate that both cAMP and PPAR $\gamma$ may be linked to ABA's antidiabetic effects.

\section{ABA and Cardiovascular Disease}

In addition to T2D and obesity-related inflammation, our laboratory has also investigated whether dietary ABA may reduce cardiovascular disease (CVD) risk. When fed to ApoE-deficient mice as part of a high-fat diet for 12 weeks, ABA treatment significantly improved atherosclerosis lesions and atherosclerosis-related hypertension, reduced $\mathrm{F} 4 / 80^{+} \mathrm{CD} 11 \mathrm{~b}^{+}$macrophage infiltration and $\mathrm{CD} 4^{+}$lymphocyte infiltration into the aortic root, decreased aortic root inflammatory lesions, and decreased aortic expression of VCAM-1 and MCP-1 [23]. ABA also increased aortic eNOS expression, both in vivo and in vitro in human aortic endothelial cells (HAECs) [23]. Short-term (10 minute) stimulation with ABA in HAECs also increased intracellular cAMP and NO release [23], an effect that is likely independent of binding to and activation of PPAR $\gamma$.

Despite our consistent anti-inflammatory in vivo findings, the effect of ABA on inflammation is somewhat ambiguous. In vitro studies from Bruzzone et al. [30], Magnone et al. [44], and Bordrato et al. [45] suggest that $\mathrm{ABA}$ has proinflammatory effects as well. In their work which principally dealt with ABA's potential effect on atherogenesis, Magnone et al. show that treatment of monocytes with ABA activates NF- $\kappa$ B and increases MCP-1 and MMP-9 release [44]. ABA also increased aortic smooth muscle cell proliferation and migration and was found at 10 -fold higher concentrations in human arterial plaques compared to normal arterial tissue [44]. An alternative explanation is that ABA levels are greater in atherosclerotic plaques as a part of an endogenous regulatory mechanism designed to minimize inflammatory lesion development during atherosclerosis. This alternative explanation would be consistent with our in vivo findings in ApoE mice [23], a well established model of atherosclerosis. Ultimately, the discrepancy between both reports as to whether ABA treatment is anti- or proinflammatory highlights an incomplete understanding of the mechanisms of immune modulation by $\mathrm{ABA}$ and suggests possible opposing effects depending on cellular and environmental conditions.

Our most recent studies with ABA in a model of colitis suggest that its anti-inflammatory effects may depend on 
TABLE 1: Summary of activities of novel classes of peroxisome proliferator-activated receptor (PPAR) agonists.

\begin{tabular}{|c|c|c|c|}
\hline & Punicic acid & Catalpic acid & Abscisic acid \\
\hline PPAR $\alpha$ reporter activity ${ }^{1}$ & Yes & Yes & No \\
\hline $\operatorname{PPAR} \gamma$ reporter activity ${ }^{1}$ & Yes & No & Yes \\
\hline $\operatorname{PPAR} \delta$ reporter activity ${ }^{1}$ & No & Unknown & No \\
\hline PPAR $\gamma$ ligand-binding activity ${ }^{2}$ & Yes & Yes & No \\
\hline PPAR $\gamma$ in silico Docking ${ }^{3}$ & Yes & Yes & No \\
\hline $\begin{array}{l}\text { Changes in PPAR-responsive } \\
\text { genes in } v i v o^{4}\end{array}$ & $\begin{array}{l}\operatorname{PPAR} \alpha \text { in adipose tissue } \\
\operatorname{PPAR} \gamma \text { in skeletal muscle }\end{array}$ & $\operatorname{PPAR} \alpha$ in adipose tissue & $\operatorname{PPAR} \gamma$ in adipose tissue \\
\hline $\begin{array}{l}\text { Efficacy in tissue-specific } \\
\text { PPAR } \gamma \text { null mice }\end{array}$ & Impaired & Unknown & Impaired \\
\hline $\begin{array}{l}\text { PPAR-independent } \\
\text { Mechanisms }\end{array}$ & $\begin{array}{c}\text { Modulation of eicosanoid } \\
\text { synthesis }\end{array}$ & $\begin{array}{c}\text { Decreases cyclooxygenase- } 2 \\
\text { expression }\end{array}$ & $\begin{array}{l}\text { Lantionine synthetase } \\
\text { component C-like } 2 \text {, cAMP, } \\
\text { and protein kinase A }\end{array}$ \\
\hline Proposed utilities & $\begin{array}{l}\text { Gut Anti-inflammatory } \\
\text { Blood sugar control } \\
\text { Immune modulator }\end{array}$ & $\begin{array}{l}\text { Antiobesity } \\
\text { Lipid-lowering } \\
\text { Anticancer }\end{array}$ & $\begin{array}{l}\text { Systemic } \\
\text { anti-inflammatory } \\
\text { Blood sugar control } \\
\text { Antiatherosclerotic } \\
\text { Immune modulator }\end{array}$ \\
\hline
\end{tabular}

${ }^{1} \operatorname{PPAR} \alpha, \gamma$, and $\delta$ reporter activity assays were conducted as previously described [22].

${ }^{2}$ PPAR $\gamma$ ligand-binding assay was performed using a commercially available competitive tracer displacement kit as previously described [42].

${ }^{3}$ Molecular modeling and docking studies were performed as previously described [27, 43].

${ }^{4}$ PPAR-responsive gene expression was measured in vivo as previously described [12].

$\mathrm{T}$ cells, and such findings may also hold relevance in its attenuation of CVD risk in ApoE-deficient mice. In the DSS model of inflammatory bowel disease (IBD), we have found that 5 weeks of ABA supplementation significantly improves colitis severity and decreases cellular adhesion molecule and proinflammatory cytokine expression in the colon [46]. The values we observed in this model were much more substantial than those found in the aortas of ApoE-deficient mice. Moreover, these beneficial effects of ABA in this model were impaired in T-cell-specific PPAR $\gamma$ knockout mice. This outcome occurred despite fully functional PPAR $\gamma$ in macrophages and epithelial cells; the main cell types involved in the immunopathogenesis of IBD and in the DSS model of colitis. $\mathrm{CD}^{+} \mathrm{CD} 25^{+} \mathrm{FoxP} 3^{+}$regulatory $\mathrm{T}$ cells appeared to be important in ABA's anti-inflammatory mechanism in these IBD studies, as well as the protein CTLA-4, which was enhanced on $\mathrm{CD}^{+} \mathrm{T}$ cells by $\mathrm{ABA}$ in vitro through a PPAR $\gamma$-dependent mechanism [46]. These recent findings in our colitis model corroborate earlier results indicating the importance of immune cells in ABA's anti-inflammatory mechanism and link T cell PPAR $\gamma$ with ABA's systemic antiinflammatory effects.

\section{Conjugated Linolenic Acid Isomers in Obesity-Related Complications}

Conjugated linolenic acids (CLnAs) or conjugated triene fatty acids are found as triglycerides in the seed oils of some plants belonging to the Punicaceae, Bignoniaceae, Rosaceae, Curcubitaceae, and Euphorbiaceae families [47]. Glycerides from these plant sources provide an easily accessible source of these unusual types of fatty acids, including but not limited to punicic (PUA), jacaric acid (JAA) catalpic (CAA), and eleostearic acids (ESA); all of which have demonstrated some promising health effects by acting as dual or panagonists of PPARs $[12,25,26]$. Of note, PUA is a conjugated octadecatrienoic acid containing c9, t11, and c13 double bonds that resembles the cis-9, trans-11 conjugated linoleic acid (CLA) isomer, a predominant CLA isomer in nature, ranging from 0.34 to $1.07 \%$ of the total fat in dairy products $[48,49]$. Interestingly, CLA has shown efficacy both as an immune modulatory nutraceutical [49] as well as a possible antiobesity therapeutic [50]. Although CLA is beyond the scope of the present paper (see [50] for a thorough review), some of the health effects of CLnAs resemble those of CLA.

\section{PUA in Type II Diabetes and Obesity-Related Inflammation}

PUA also known as trichosanic acid is a conjugated triene fatty acid naturally found at high concentrations in the seed of Punica granatum (Punicaceae, Pomegranate) [51] and Trichosanthes kirilowii [47]. PUA constitutes 64-83 percent of the pomegranate seed oil (PSO) $[52,53]$, but it also contains minor amounts of ESA, CAA, and JAA [51]. Phytosterols (i.e., beta-sitosterol, campesterol, and stigmasterol) were also found in quite high concentrations in the PSO (4,089$6,205 \mathrm{mg} / \mathrm{kg}$ ), about 3-4-fold higher than in soybean oil [53]. We recently demonstrated a dose-dependent increase in the ability of PUA to activate PPAR $\alpha$ and $\gamma$ reporter activity in 3T3-L1 cells and to bind to PPAR $\gamma$ and $\delta$ ligandbinding domain [25]. In line with these in vitro findings, we also demonstrated that oral PUA administration ameliorated fasting plasma glucose concentrations and as well as the 
glucose normalizing ability during a glucose tolerance test in $\mathrm{db} / \mathrm{db}$ mice, suggesting that PUA prevents or ameliorates type 2 diabetes. These improvements in disease markers were accompanied with upregulation of $\operatorname{PPAR} \alpha$-responsive genes in skeletal muscle and both $\operatorname{PPAR} \alpha$ - and $\gamma$-responsive genes in intra-abdominal white adipose tissue [25]. Like CLA, PUA also suppressed the expression of inflammatory cytokines such as TNF- $\alpha$ and NF- $\kappa$ B activation. Furthermore, the deletion of the PPAR $\gamma$ gene from immune cells abrogated the beneficial effect of PUA on glucose normalization and impaired PUA's anti-inflammatory effect, thereby suggesting that PUA ameliorates metabolic and inflammatory changes associated with obesity, in part, through a PPAR $\gamma$-dependent mechanism. We have also demonstrated that PUA is safe in acute toxicity studies in rats [54]. We also demonstrated that PUA treatment increased the expression of PPAR $\delta$ in pancreatic tissue (unpublished observation from our group), suggesting that this isoform may be a potentially interesting mediator of some of the insulin-sensitizing effects of PUA. Based on the phenotype observed during PUA treatment, the response of skeletal muscle could also be PPAR $\delta$ mediated, although no evidence of such effect is available at the moment.

\section{CAA in Obesity and Type II Diabetes}

Catalpic acid (CAA) is a conjugated triene fatty acid (trans9, trans-11, cis-13 CLnA) naturally found at high concentrations in the seed of plants in the Catalpa Scop. Genus, belonging to the Bignoniaceae family. CAA-producing plants comprise 11 species of trees and shrubs native to East Africa and America, including Catalpa ovata, Catalpa speciosa, Catalpa bungei, and Catalpa bignonioides (southern catalpa) of the family Bignoniaceae. CAA constitutes approximately $60 \%$ of the oil of the catalpa seed oil. Even though the putative medicinal properties of catalpa trees have been alleged for centuries as a part of popular folklore, little is known about the effects of CAA on chronic conditions afflicting today's developed societies such as obesity and type 2 diabetes. For instance, the biological activities of extracts from Catalpa bignonioides have been investigated in recent years [55].

We found that oral CAA administration decreased abdominal fat accumulation, improved glucose homeostasis, increased plasma HDL cholesterol concentrations, increased plasma HDL cholesterol concentrations, and decreases plasma TG levels in mice fed high-saturated fat diets [26]. The lipid-lowering actions of CAA are consistent with the PPAR $\alpha$ agonistic actions of fibrates [56]. Of note, fibrates increase HDL cholesterol through a PPAR $\alpha$-induced transcriptional activation of liver $\mathrm{X}$ receptor, a nuclear receptor that increases reverse cholesterol transport through promotion of the ATP-binding cassette transporters ABCA-1 and ABCG-1 [57-59]. Additionally, real time RT-PCR results demonstrated that PPAR $\alpha$ and PPAR $\alpha$-responsive genes are upregulated in WAT of mice administered CAA, whereas PPAR $\gamma$ and $\delta$ expression were not significantly affected by CAA in WAT. These data suggest that the metabolic effects of CAA on glucose and lipid metabolism may be mediated through a PPAR $\alpha$-dependent mechanism. In contrast to ABA and PUA that modulate obesity comorbidities (i.e., insulin resistance, diabetes, or systemic inflammation), CAA has a direct effect in reducing adipose tissue accumulation.

\section{Concluding Remarks and Future Directions}

While diet and exercise remain the recommended approaches to prevent and treat obesity and its comorbidities, nutraceuticals and drugs may play a role as adjunct therapeutic interventions for controlling certain aspects of the disease etiopathogenesis. Mounting evidence demonstrates that naturally occurring compounds such as ABA, PUA, and CAA can act on well-established pharmacologic targets such as PPARs and exert their antidiabetic, anti-inflammatory, or antiobesity properties in animal models. In contrast to synthetic agonists of PPARs, these plant-derived compounds are safer and may act through multiple molecular targets. Intervention studies in humans are necessary to determine whether the beneficial effects reported in mice translate into clinical improvements in obese, diabetic, or insulin-resistant individuals.

With regard to the further developments of these compounds, based on the results reported here, CAA will be further developed for antiobesity and lipid-lowering applications, PUA will be developed for regulating blood sugar levels as well as controlling intestinal inflammation, and ABA will be developed for improving insulin sensitivity as a potential safer alternative to TZD and a systemic anti-inflammatory compound. Additionally, we will investigate the possibility of synergistic interactions between these compounds and drugs or other natural products to maximize their efficacy.

\section{References}

[1] S. D. H. Malnick and H. Knobler, "The medical complications of obesity,” QJM, vol. 99, no. 9, pp. 565-579, 2006.

[2] E. A. Finkelstein, J. G. Trogdon, J. W. Cohen, and W. Dietz, "Annual medical spending attributable to obesity: payer-and service-specific estimates," Health Affairs, vol. 28, no. 5, pp. w822-w831, 2009.

[3] The United Health Federation, The American Public Health Association, and partnership for prevention, "The future costs of obesity: national and state estimates of the impact of obesity on direct heaalth care expenses," 2009, http://www .americashealthrankings.org/2009/spotlight.Aspx.

[4] A. H. Mokdad, B. A. Bowman, E. S. Ford, F. Vinicor, J. S. Marks, and J. P. Koplan, "The continuing epidemics of obesity and diabetes in the United States," Journal of the American Medical Association, vol. 286, no. 10, pp. 1195-1200, 2001.

[5] B. Desvergne and W. Wahli, "Peroxisome proliferatoractivated receptors: nuclear control of metabolism," Endocrine Reviews, vol. 20, no. 5, pp. 649-688, 1999.

[6] R. W. Nesto, D. Bell, R. O. Bonow et al., "Thiazolidinedione use, fluid retention, and congestive heart failure: a consensus statement from the american heart association and american diabetes association," Circulation, vol. 108, no. 23, pp. 29412948, 2003. 
[7] K. Katayama, K. Wada, A. Nakajima et al., "A novel PPAR $\gamma$ gene therapy to control inflammation associated with inflammatory bowel disease in a murine model," Gastroenterology, vol. 124, no. 5, pp. 1315-1324, 2003.

[8] L. Dubuquoy, E. Å. Jansson, S. Deeb et al., "Impaired expression of peroxisome proliferator-activated receptor $\gamma$ in ulcerative colitis," Gastroenterology, vol. 124, no. 5, pp. 12651276, 2003.

[9] D. J. Mangelsdorf, C. Thummel, M. Beato et al., "The nuclear receptor super-family: the second decade," Cell, vol. 83, no. 6, pp. 835-839, 1995.

[10] J. Bassaganya-Riera, A. Guri, J. King, and R. Hontecillas, "Peroxisome proliferator-activated receptors: the nutritionally controlled molecular networks that integrate inflammation, immunity and metabolism," Current Nutrition < Food Science, vol. 1, pp. 179-187, 2005.

[11] J. M. Lehmann, L. B. Moore, T. A. Smith-Oliver, W. O. Wilkison, T. M. Willson, and S. A. Kliewer, "An antidiabetic thiazolidinedione is a high affinity ligand for peroxisome proliferator-activated receptor $\gamma$ (PPAR $\gamma)$," Journal of Biological Chemistry, vol. 270, no. 22, pp. 12953-12956, 1995.

[12] J. Bassaganya-Riera, K. Reynolds, S. Martino-Catt et al., "Activation of PPAR $\gamma$ and $\delta$ by conjugated linoleic acid mediates protection from experimental inflammatory bowel disease," Gastroenterology, vol. 127, no. 3, pp. 777-791, 2004.

[13] J. D. Lewis, A. M. Capra, N. S. Achacoso et al., "Thiazolidinedione therapy is not associated with increased colonic neoplasia risk in patients with diabetes mellitus," Gastroenterology, vol. 135, no. 6, pp. 1914-1923.e1, 2008.

[14] N. P. Evans, S. A. Misyak, E. M. Schmelz, A. J. Guri, R. Hontecillas, and J. Bassaganya-Riera, "Conjugated linoleic acid ameliorates inflammation-induced colorectal cancer in mice through activation of PPAR $\gamma$," Journal of Nutrition, vol. 140, no. 3, pp. 515-521, 2010.

[15] S. Ogino, K. Shima, Y. Baba et al., "Colorectal cancer expression of peroxisome proliferator-activated receptor $\gamma$ (PPARG, PPARgamma) is associated with good prognosis," Gastroenterology, vol. 136, no. 4, pp. 1242-1250, 2009.

[16] J. R. Aldridge, C. E. Moseley, D. A. Boltz et al., "TNF/iNOSproducing dendritic cells are the necessary evil of lethal influenza virus infection," Proceedings of the National Academy of Sciences of the United States of America, vol. 106, no. 13, pp. 5306-5311, 2009.

[17] F. Ismail-Beigi, T. Craven, M. A. Banerji et al., "Effect of intensive treatment of hyperglycaemia on microvascular outcomes in type 2 diabetes: an analysis of the ACCORD randomised trial," The Lancet, vol. 376, no. 9739, pp. 419-430, 2010.

[18] M. H. Davidson, A. Armani, J. M. McKenney, and T. A. Jacobson, "Safety considerations with fibrate therapy," American Journal of Cardiology, vol. 99, no. 6, pp. S3-S18, 2007.

[19] A. J. Guri, R. Hontecillas, and J. Bassaganya-Riera, "Abscisic acid ameliorates experimental IBD by downregulating cellular adhesion molecule expression and suppressing immune cell infiltration," Clinical Nutrition, vol. 29, no. 6, pp. 824-831, 2010.

[20] A. J. Guri, R. Hontecillas, and J. Bassaganya-Riera, "Abscisic acid synergizes with rosiglitazone to improve glucose tolerance and down-modulate macrophage accumulation in adipose tissue: possible action of the cAMP/PKA/PPAR $\gamma$ axis," Clinical Nutrition, vol. 29, no. 5, pp. 646-653, 2010.
[21] A. J. Guri, R. Hontecillas, G. Ferrer et al., "Loss of PPAR $\gamma$ in immune cells impairs the ability of abscisic acid to improve insulin sensitivity by suppressing monocyte chemoattractant protein-1 expression and macrophage infiltration into white adipose tissue," Journal of Nutritional Biochemistry, vol. 19, no. 4, pp. 216-228, 2008.

[22] A. J. Guri, R. Hontecillas, H. Si, D. Liu, and J. BassaganyaRiera, "Dietary abscisic acid ameliorates glucose tolerance and obesity-related inflammation in $\mathrm{db} / \mathrm{db}$ mice fed high-fat diets," Clinical Nutrition, vol. 26, no. 1, pp. 107-116, 2007.

[23] A. J. Guri, S. A. Misyak, R. Hontecillas et al., "Abscisic acid ameliorates atherosclerosis by suppressing macrophage and $\mathrm{CD}^{+} \mathrm{T}$ cell recruitment into the aortic wall," Journal of Nutritional Biochemistry, vol. 21, no. 12, pp. 1178-1185, 2010.

[24] J. Bassaganya-Riera, J. Skoneczka, D. G. J. Kingston et al., "Mechanisms of action and medicinal applications of abscisic acid," Current Medicinal Chemistry, vol. 17, no. 5, pp. 467-478, 2010.

[25] R. Hontecillas, M. O’Shea, A. Einerhand, M. Diguardo, and J. Bassaganya-Riera, "Activation of PPAR $\gamma$ and $\alpha$ by punicic acid ameliorates glucose tolerance and suppresses obesity-related inflammation," Journal of the American College of Nutrition, vol. 28, no. 2, pp. 184-195, 2009.

[26] R. Hontecillas, M. Diguardo, E. Duran, M. Orpi, and J. Bassaganya-Riera, "Catalpic acid decreases abdominal fat deposition, improves glucose homeostasis and upregulates PPAR $\alpha$ expression in adipose tissue," Clinical Nutrition, vol. 27, no. 5, pp. 764-772, 2008.

[27] SN Lewis, J Bassaganya-Riera, and DR. Bevan, "Virtual screening as a technique for ppar modulator discovery," PPAR Research, vol. 2010, Article ID 861238, 10 pages, 2010.

[28] B. Alberts, “The breakthroughs of 2009," Science, vol. 326, no. 5960, p. 1589, 2009.

[29] S. R. Cutler, P. L. Rodriguez, R. R. Finkelstein, and S. R. Abrams, "Abscisic acid: emergence of a core signaling network," Annual Review of Plant Biology, vol. 61, pp. 651-679, 2010.

[30] S. Bruzzone, I. Moreschi, C. Usai et al., "Abscisic acid is an endogenous cytokine in human granulocytes with cyclic ADP-ribose as second messenger," Proceedings of the National Academy of Sciences of the United States of America, vol. 104, no. 14, pp. 5759-5764, 2007.

[31] L. Sturla, C. Fresia, L. Guida et al., "LANCL2 is necessary for abscisic acid binding and signaling in human granulocytes and in rat insulinoma cells," Journal of Biological Chemistry, vol. 284, no. 41, pp. 28045-28057, 2009.

[32] A. J. Guri, R. Hontecillas, and J. Bassaganya-Riera, "Peroxisome proliferator-activated receptors: bridging metabolic syndrome with molecular nutrition," Clinical Nutrition, vol. 25, no. 6, pp. 871-885, 2006.

[33] J. I. Odegaard, R. R. Ricardo-Gonzalez, M. H. Goforth et al., "Macrophage-specific PPAR $\gamma$ controls alternative activation and improves insulin resistance," Nature, vol. 447, no. 7148, pp. 1116-1120, 2007.

[34] A. W. Norris, M. F. Hirshman, J. Yao et al., "Endogenous peroxisome proliferator-activated receptor- $\gamma$ augments fatty acid uptake in oxidative muscle," Endocrinology, vol. 149, no. 11, pp. 5374-5383, 2008.

[35] T. Tanaka, H. Masuzaki, K. Ebihara et al., "Transgenic expression of mutant peroxisome proliferator-activated receptor $\gamma$ in liver precipitates fasting-induced steatosis but protects against high-fat diet-induced steatosis in mice," Metabolism, vol. 54, no. 11, pp. 1490-1498, 2005. 
[36] C. Evans-Molina, R. D. Robbins, T. Kono et al., "Peroxisome proliferator-activated receptor $\gamma$ activation restores islet function in diabetic mice through reduction of endoplasmic reticulum stress and maintenance of euchromatin structure," Molecular and Cellular Biology, vol. 29, no. 8, pp. 2053-2067, 2009.

[37] P. S. Chaggar, S. M. Shaw, and S. G. Williams, "Review article: thiazolidinediones and heart failure," Diabetes \& Vascular Disease Research, vol. 6, no. 3, pp. 146-152, 2009.

[38] S. P. Weisberg, D. Hunter, R. Huber et al., "CCR2 modulates inflammatory and metabolic effects of high-fat feeding," Journal of Clinical Investigation, vol. 116, no. 1, pp. 115-124, 2006.

[39] N. Kamei, K. Tobe, R. Suzuki et al., "Overexpression of monocyte chemoattractant protein-1 in adipose tissues causes macrophage recruitment and insulin resistance," Journal of Biological Chemistry, vol. 281, no. 36, pp. 26602-26614, 2006.

[40] S. Bruzzone, N. Bodrato, C. Usai et al., "Abscisic acid is an endogenous stimulator of insulin release from human pancreatic islets with cyclic ADP ribose as second messenger," Journal of Biological Chemistry, vol. 283, no. 47, pp. 32188 32197, 2008.

[41] G. Lazennec, L. Canaple, D. Saugy, and W. Wahli, "Activation of peroxisome proliferator-activated receptors (PPARs) by their ligands and protein kinase A activators," Molecular Endocrinology, vol. 14, no. 12, pp. 1962-1975, 2000.

[42] J. Bassaganya-Riera, A. J. Guri, P. Lu et al., "Abscisic acid regulates inflammation via ligand-binding domain-independent activation of ppar gamma," Journal of Biological Chemistry. In press.

[43] P. Lu, D. R. Bevan, S. N. Lewis, R. Hontecillas, and J. Bassaganya-Riera, "Molecular modeling of lanthionine synthetase component C-like protein 2: a potential target for the discovery of novel type 2 diabetes prophylactics and therapeutics," Journal of Molecular Modeling. In press.

[44] M. Magnone, S. Bruzzone, L. Guida et al., "Abscisic acid released by human monocytes activates monocytes and vascular smooth muscle cell responses involved in atherogenesis," Journal of Biological Chemistry, vol. 284, no. 26, pp. 17808 17818, 2009.

[45] N. Bodrato, L. Franco, C. Fresia et al., "Abscisic acid activates the murine microglial cell line N9 through the second messenger cyclic ADP-ribose," Journal of Biological Chemistry, vol. 284, no. 22, pp. 14777-14787, 2009.

[46] A. J. Guri, R. Hontecillas, and J. Bassaganya-Riera, "Abscisic acid ameliorates experimental IBD by downregulating cellular adhesion molecule expression and suppressing immune cell infiltration," Clinical Nutrition, vol. 29, no. 6, pp. 824-831, 2010.

[47] Y. G. Joh, S. J. Kim, and W. W. Christie, "The structure of the triacylglycerols, containing punicic acid, in the seed oil of Trichosanthes kirilowii," Journal of the American Oil Chemists' Society, vol. 72, no. 9, pp. 1037-1042, 1995.

[48] J. Bassaganya-Riera, R. Hontecillas, and D. C. Beitz, "Colonic anti-inflammatory mechanisms of conjugated linoleic acid," Clinical Nutrition, vol. 21, no. 6, pp. 451-459, 2002.

[49] M. O'Shea, J. Bassaganya-Riera, and I. C. Mohede, "Immunomodulatory properties of conjugated linoleic acid," The American journal of clinical nutrition, vol. 79, no. 6, pp. 1199S-1206S, 2004.

[50] A. Kennedy, K. Martinez, S. Schmidt, S. Mandrup, K. LaPoint, and M. McIntosh, "Antiobesity mechanisms of action of conjugated linoleic acid," Journal of Nutritional Biochemistry, vol. 21, no. 3, pp. 171-179, 2010.
[51] G. Sassano, P. Sanderson, J. Franx, P. Groot, J. Van Straalen, and J. Bassaganya-Riera, "Analysis of pomegranate seed oil for the presence of jacaric acid," Journal of the Science of Food and Agriculture, vol. 89, no. 6, pp. 1046-1052, 2009.

[52] N. H. E. Ahlers, A. C. Dennison, and L. A. O'Neill, "Spectroscopic examination of punicic acid," Nature, vol. 173, no. 4413, pp. 1045-1046, 1954.

[53] M. Kaufman and Z. Wiesman, "Pomegranate oil analysis with emphasis on MALDI-TOF/MS triacylglycerol fingerprinting," Journal of Agricultural and Food Chemistry, vol. 55, no. 25, pp. 10405-10413, 2007.

[54] I. A. T. M. Meerts, C. M. Verspeek-Rip, C. A. F. Buskens et al., "Toxicological evaluation of pomegranate seed oil," Food and Chemical Toxicology, vol. 47, no. 6, pp. 1085-1092, 2009.

[55] D. Muñoz-Mingarro, N. Acero, F. Llinares et al., "Biological activity of extracts from Catalpa bignonioides Walt. (Bignoniaceae)," Journal of Ethnopharmacology, vol. 87, no. 2-3, pp. 163-167, 2003.

[56] J. Remick, H. Weintraub, R. Setton, J. Offenbacher, E. Fisher, and A. Schwartzbard, "Fibrate therapy: an update," Cardiology in Review, vol. 16, no. 3, pp. 129-141, 2008.

[57] A. Chawla, W. A. Boisvert, C. H. Lee et al., "A PPAR $\gamma$-LXRABCA1 pathway in macrophages is involved in cholesterol efflux and atherogenesis," Molecular Cell, vol. 7, no. 1, pp. 161$171,2001$.

[58] R. Walczak and P. Tontonoz, "PPARadigms and PPARadoxes: expanding roles for PPAR $\gamma$ in the control of lipid metabolism," Journal of Lipid Research, vol. 43, no. 2, pp. 177-186, 2002.

[59] G. Chinetti, S. Lestavel, V. Bocher et al., "PPAR- $\alpha$ and PPAR- $\gamma$ activators induce cholesterol removal from human macrophage foam cells through stimulation of the ABCA1 pathway," Nature Medicine, vol. 7, no. 1, pp. 53-58, 2001. 


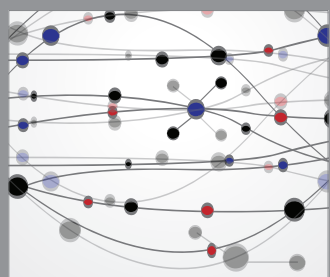

The Scientific World Journal
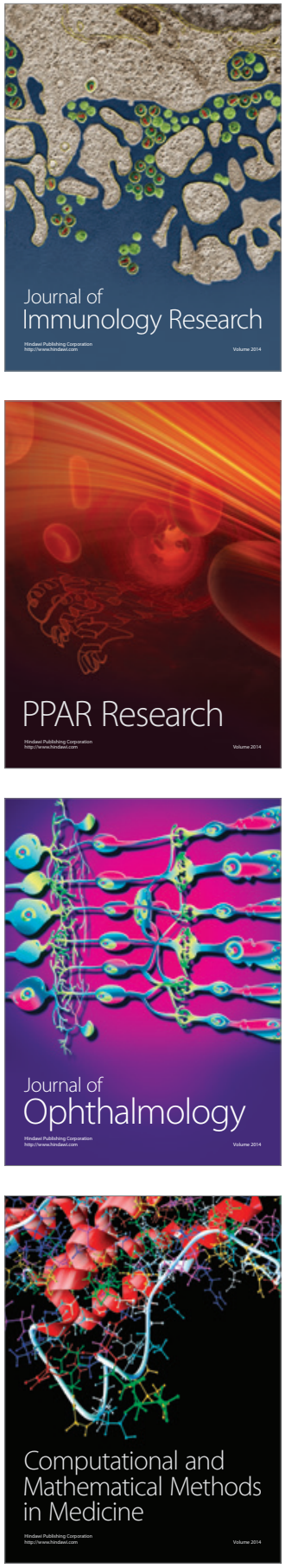

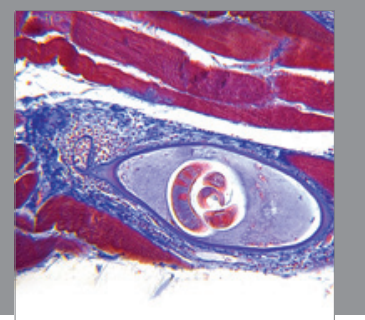

Gastroenterology

Research and Practice
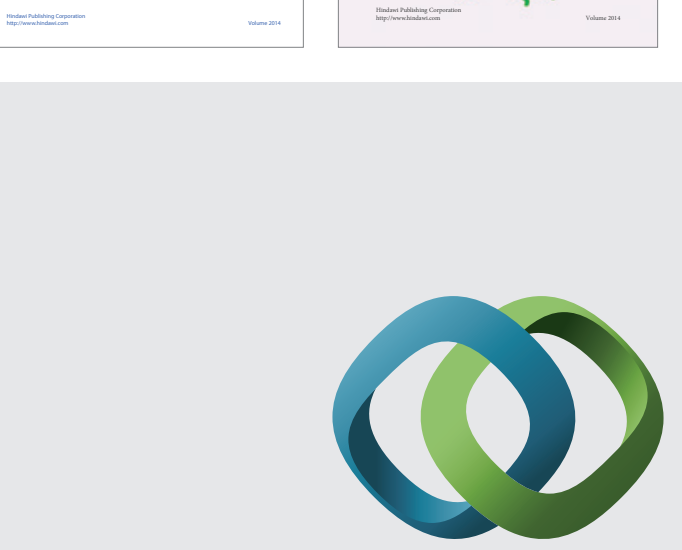

\section{Hindawi}

Submit your manuscripts at

http://www.hindawi.com
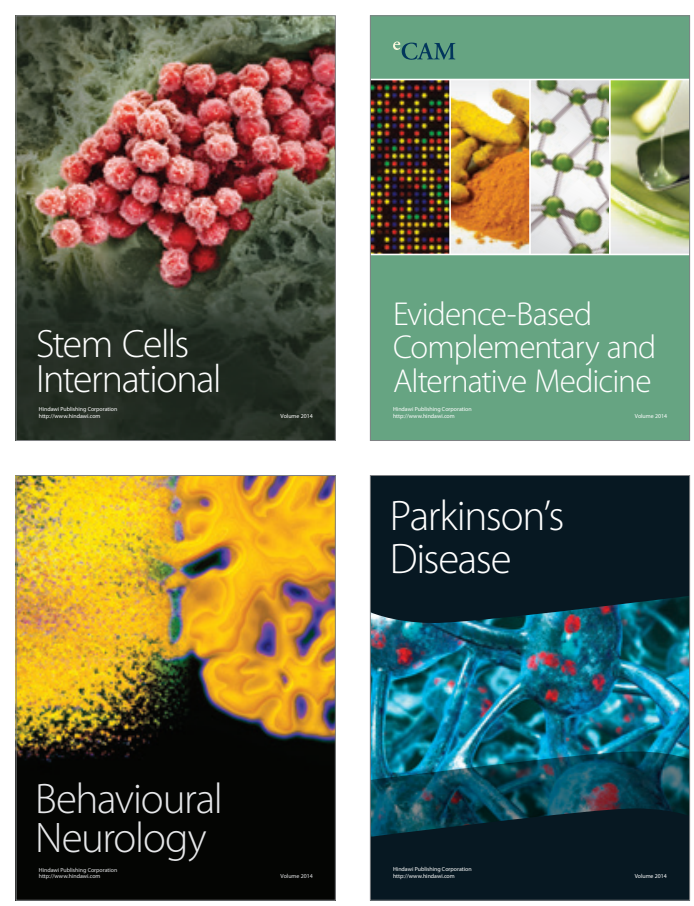

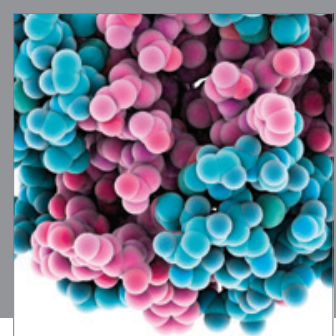

Journal of
Diabetes Research

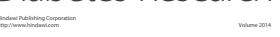

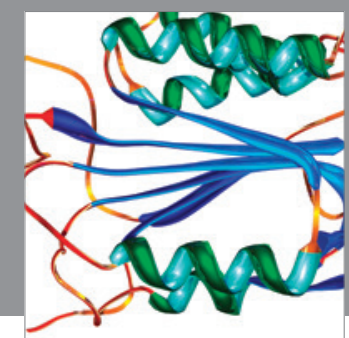

Disease Markers
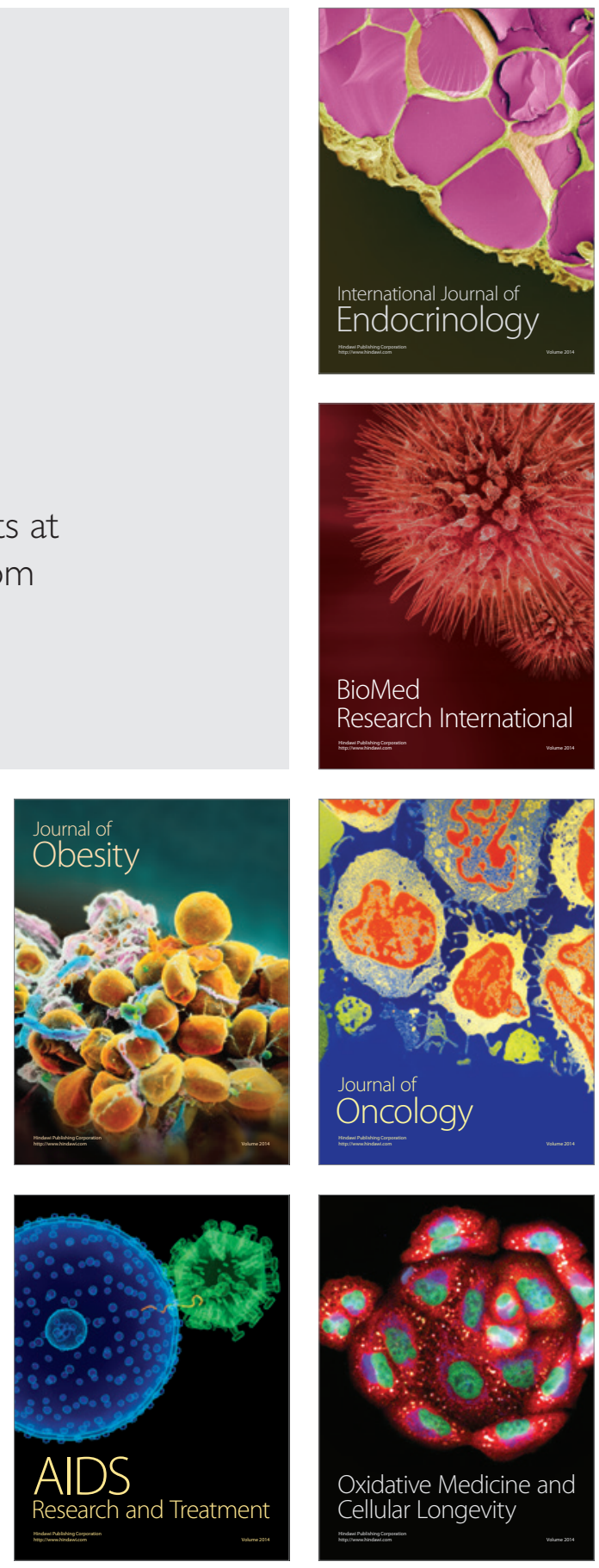